\title{
Cyanobacteria from coastal lagoons of Southern Brazil: coccoid organisms
}

\author{
MARIÉLLEN DORNELLES MARTINS ${ }^{1,3}$, LUIS HENRIQUE ZANINI BRANCO ${ }^{1}$ and \\ VERA REGINA WERNER ${ }^{2}$
}

(received: February 03, 2011; accepted: January 26, 2012)

\begin{abstract}
Cyanobacteria from coastal lagoons of Southern Brazil: coccoid organisms) Considering the great ecological importance of the cyanobacteria and the need for more detailed information about these organisms in Brazilian waters, this paper provides taxonomic information about the unicellular cyanobacteria flora in lagoon systems along the coastal plains of Rio Grande do Sul State. Sampling was performed in different freshwater bodies along the eastern (Casamento Lake area) and western (near the city of Tapes) banks of the Patos Lagoon $\left(30^{\circ} 40^{\prime} \mathrm{S}-30^{\circ} 10^{\prime} \mathrm{S}\right.$ and $\left.50^{\circ} 30^{\prime} \mathrm{W}-51^{\circ} 30^{\prime} \mathrm{W}\right)$. The samples were collected once in the rainy season and once in the dry season (from May 2003 to December 2003) using a plankton net $(25 \mu \mathrm{m}$ mesh) in pelagic and littoral zones, and by squeezing the submerged parts of aquatic macrophytes. Thirty one species belonging to the families Synechoccocaceae (7 taxa), Merismopediaceae (12 taxa), Chamaesiphonaceae (1 taxon), Microcystaceae (4) and Chroococcaceae (7 taxa) were identified. Among these species, five are reported for the first time in Rio Grande do Sul State: Chamaesiphon amethystinus (Rostafinski) Lemmermann, Chroococcus minimus (Keissler) Lemmermann, Coelomoron pusillum (Van Goor) Komárek, Coelosphaerium kuetzingeanum Naegeli, and Cyanodictyon tubiforme Cronberg.
\end{abstract}

Key words - Casamento lake, Chroococcales, Patos Lagoon, Synechococcales

\section{INTRODUCTION}

Coastal lagoons are shallow aquatic environments that develop at the interface between coastal terrestrial and marine ecosystems and have high natural productivity as compared to oceanic or adjacent coastal ecosystems (Margalef 1969). Although lagoons are intricately connected to their surrounding environments, they have unique structural and functional mechanisms that result in specific biological productivities and carrying capacities (Terwilliger \& Wolflin 2005).

Continental and marine environments influence coastal lagoons. Coastal regions have historically been prone to human habitation, and the resulting rural and urban landscapes reflect human orientations toward the use of the natural capital of lagoons. Lagoons are sensitive areas that play an important role among coastal ecosystems in providing suitable breeding areas for many species, but many lagoons are currently deteriorating because of overuse of their natural capital. Fisheries and aquaculture, tourism, and urban, industrial and agricultural developments are typical uses that are usually not well controlled, and lagoon resources are frequently overexploited - so that their present quality

1. Universidade Estadual Paulista Júlio de Mesquita Filho, Departamento de Zoologia e Botânica, Instituto de Biociências, Letras e Ciências Exatas, São José do Rio Preto, SP, Brazil

2. Fundação Zoobotânica do Rio Grande do Sul, Museu de Ciências Naturais, Porto Alegre, RS, Brazil

3._Corresponding author: marinhadm@yahoo.com.br and future capability to sustain productivity is being seriously compromised (Göneng \& Wolflin 2005).

There are important coastal lagoons systems along the southern Atlantic coast of South America that comprise a diversity of freshwater lakes not found anywhere else in the world. These aquatic systems are inserted with in a mosaic of heterogeneous terrestrial ecosystems - resulting in great biological diversity.

Cyanobacteria have important roles in aquatic systems and they make up part of the planktic, metaphytic, or benthic communities, representing the base of trophic chain; they are responsible for part of primary productivity of aquatic systems and are relevant in biogeochemical cycles (Wetzel 1983, Padisák 2003).

In Rio Grande do Sul State, southern Brazil, studies investigating phytoplankton community including cyanobacteria have been carried out by Callegaro et al. (1981), Torgan \& Garcia (1989), Garcia \& Vélez (1995), Torgan et al. (1995), Torgan (1997), and Cardoso \& MottaMarques $(2003,2004)$. A number of taxonomic studies concerning cyanobacteria have also been conducted by Torgan et al. (1981), Franceschini (1983, 1990), Werner (1984, 1988, 2002), Werner \& Rosa (1992), Torgan \& Paula (1994), Werner \& Sant'Anna (1998, 2000, 2006), and Werner et al. (2008). The study by Werner (2002) was the most extensive study, as well as one of the most important, conducted to date in Rio Grande do Sul State.

The present study is part of a wider project examining the fauna and flora of coastal ecosystems of Rio Grande do Sul, Brazil. 


\section{MATERIAL AND METHODS}

Samples were taken from different freshwater bodies on the eastern (Casamento lake area) and western (Tapes City area) banks of the Patos Lagoon $\left(30^{\circ} 40^{\prime} \mathrm{S}-30^{\circ} 10^{\prime} \mathrm{S}\right.$ and $50^{\circ} 30^{\prime} \mathrm{W}-51^{\circ} 30^{\prime} \mathrm{W}$ ) (figure 1 , table 1 ). The study area is dominated by wetland ecosystems, and the lagoons there are freshwater, shallow (Burger \& Ramos 2007) and slightly acidic (Bicca 2007).

Samples were collected once during the rainy season and once during the dry season, from May 2003 to December 2003 , using phytoplankton nets $(25 \mu \mathrm{m}$ mesh) in pelagic and littoral zones, and by squeezing the submerged parts of aquatic macrophytes.

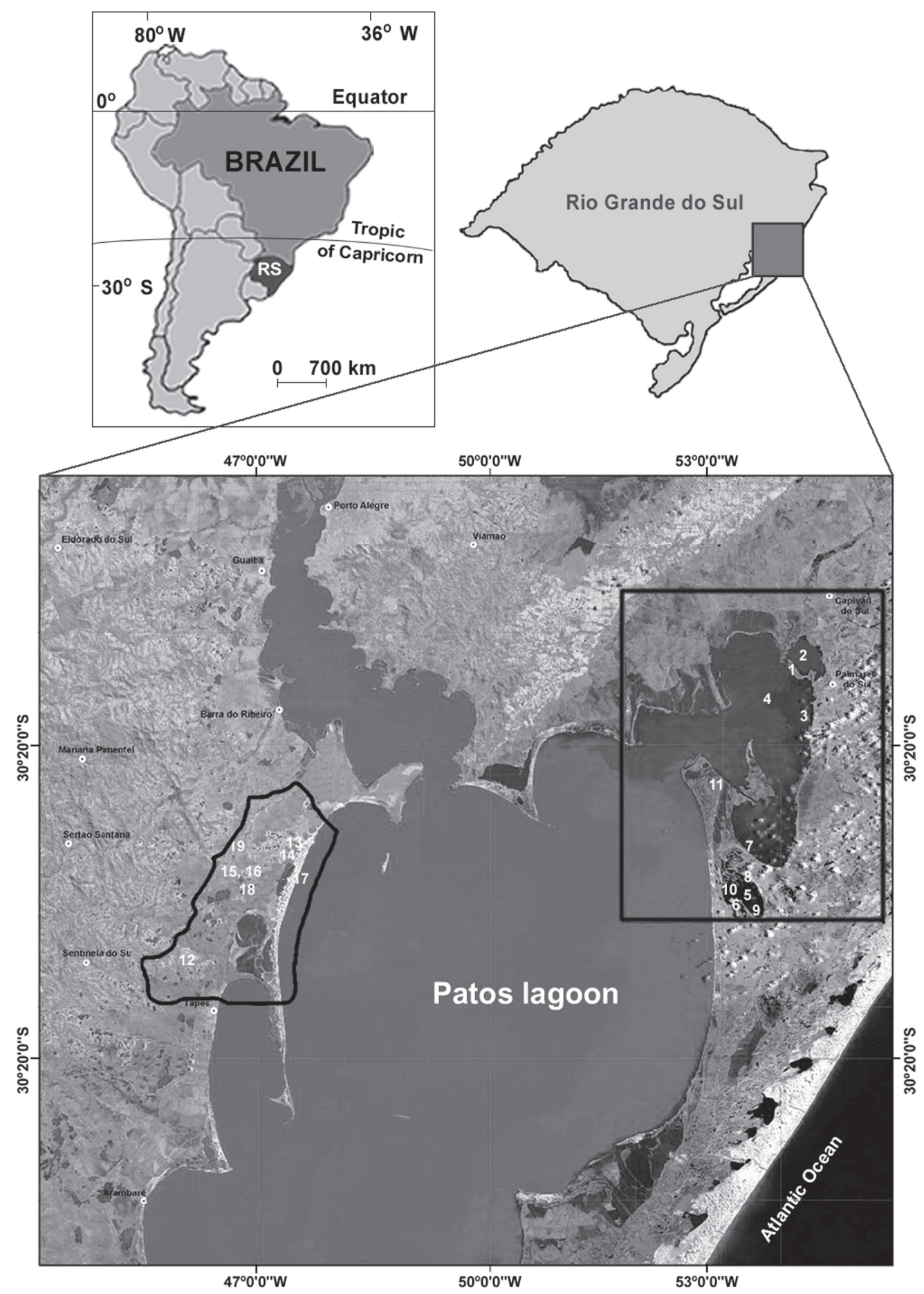

Figure 1. Map of the Casamento Lake region and the area around the city of Tapes (on the coastal plain of Rio Grande do Sul State, Brazil) (modified from Burger \& Ramos 2007). 
Table 1. Locations of the collections and their respective samples. $(\mathrm{M}=$ margin; $\mathrm{P}=$ pelagic zone; $\mathrm{UTM}=$ Universal Transverse Mercator coordinate system (zone 22); HAS = Alarich Schultz Herbarium).

\begin{tabular}{rlll}
\hline Area & & UTM & HAS \\
\hline 1 & Capivari/Casamento wetland (M) & $541830-6654326$ & HAS1043339 \\
2 & Capivari lagoon (M) & $542910-6655896$ & HAS104098, HAS104343 \\
3 & Casamento lagoon (M) & $541607-6654229$ & HAS104103, HAS104117, HAS104348, HAS104356, \\
& & & HAS104369, HAS104370, HAS104396 \\
4 & Casamento lagoon (P) & $541719-6654246$ & HAS104106, HAS104351, HAS104352 \\
5 & Gateados lagoon (M) & $532524-6621750$ & HAS104171, HAS104172, HAS104174 \\
6 & Gateados wetland & $531876-6628854$ & HAS104131, HAS104132, HAS104134 \\
7 & Spillway & $532831-6631257$ & HAS104163, HAS104167, HAS104381 \\
8 & Gateados lagoon (M) & $532053-6624520$ & HAS104142,HAS104147 \\
9 & Gateados lagoon (M) & $532285-6624514$ & HAS104153, HAS104376 \\
10 & Gateados lagoon (P) & $533263-6624909$ & HAS104150, HAS104372, HAS104399 \\
11 & Rincão do Anastácio wetland & $530749-6639690$ & HAS104118, HAS104119, HAS104124, HAS104362 \\
12 & Capivaras lagoon (M) & $473595-6629067$ & HAS104436 \\
13 & Dunas lagoon & $473435-6628655$ & HAS104230, HAS104442 \\
14 & Dunas wetland & $473603-6628803$ & HAS104234, HAS104446 \\
15 & Charutão lagoon (M) & $465956-6623899$ & HAS104195, HAS104416 \\
16 & Charutão lagoon (P) & $465745-6623421$ & HAS104197, HAS104202, HAS104420, HAS104425, \\
& HAS104450, HAS104451 \\
17 & São Miguel lagoon (M) & $464203-6623642$ & HAS104203, HAS104427 \\
18 & Redonda lagoon (M) & $465503-6622735$ & HAS104235, HAS104240 \\
19 & Araçá (M) & $461948-6626264$ & HAS104457 \\
\hline
\end{tabular}

The materials were examined using Olympus $\mathrm{BH} 2$ and Leica DMLB bright field microscopes. The structures of the mucilaginous envelopes were observed using China ink. The classification proposed by Hoffmann et al. (2005) was adopted to reflect the systematic arrangement and families and lower taxonomic levels according to Komárek \& Anagnostidis (1998).

Taxonomic descriptions, photomicrographs, and their occurrence in the aquatic environments studied were provided for all species. The abbreviation "diam." for diameter was used in the species descriptions.

The studied samples were deposited in the Prof. Alarich Schultz Herbarium (HAS, Natural Sciences Museum, Zoobotanical Foundation, Porto Alegre, Rio Grande do Sul, Brazil). The record numbers together with the list of species and occurrences are presented in tables 1 and 2, followed by the identification keys and species descriptions.

Table 2. Cyanobacteria found in coastal lagoons. $(\mathrm{WCC}=$ wetlands between the Capivari and Casamento lagoons; $\mathrm{CIL}=\mathrm{Capivari}$ lagoon; $\mathrm{CML}=$ Casamento lake; $\mathrm{GL}=$ Gateados lagoon; $\mathrm{GW}=$ Gateados wetland; $\mathrm{SP}=$ spillway; $\mathrm{PAW}=\mathrm{Pontal}$ do Anastácio wetland; $\mathrm{CAL}=$ Capivaras lagoon; $\mathrm{DL}=$ Dunas lagoon; $\mathrm{DW}=$ Dunas wetland; $\mathrm{CTL}=$ Charutão lagoon; $\mathrm{SML}=$ São Miguel lagoon; $\mathrm{RL}=$ Redonda lagoon; $\mathrm{AR}=$ Araçá).

\begin{tabular}{|c|c|c|c|c|c|c|c|c|c|c|c|c|c|c|}
\hline \multirow{2}{*}{ Species } & \multicolumn{7}{|c|}{ Casamento lagoon area } & \multicolumn{7}{|c|}{ Tapes city area } \\
\hline & WCC & $\mathrm{CIL}$ & CML & GW & BG & SP & PAW & $\mathrm{CAL}$ & DL & DW & CTL & SML & $\mathrm{RL}$ & $\mathrm{AR}$ \\
\hline Aphanocapsa delicatissima & & & $\mathrm{X}$ & & $\mathrm{X}$ & & & & & & & & $\mathrm{X}$ & \\
\hline A. elachista & & $\mathrm{X}$ & $\mathrm{X}$ & & & & & & & & & & & \\
\hline A. holsatica & & & $\mathrm{X}$ & & & $\mathrm{X}$ & & & & & & & & \\
\hline A. incerta & & & $\mathrm{X}$ & & & & & & & & & & & \\
\hline A. koordersii & & $\mathrm{X}$ & $\mathrm{X}$ & $\mathrm{X}$ & & $\mathrm{X}$ & $\mathrm{X}$ & & $\mathrm{X}$ & & $\mathrm{X}$ & $\mathrm{X}$ & & \\
\hline Aphanothece comasii & & & & $\mathrm{X}$ & & & & & & & & & & \\
\hline A. conglomerata & & & & $\mathrm{X}$ & & & & & & & & & & \\
\hline A. minutissima & & $\mathrm{X}$ & $\mathrm{X}$ & & & & & & & & $\mathrm{X}$ & & & \\
\hline A. smithii & & $\mathrm{X}$ & $\mathrm{X}$ & & & & $\mathrm{X}$ & & $\mathrm{X}$ & & $\mathrm{X}$ & & & \\
\hline A. stagnina & & & & $\mathrm{X}$ & & & $\mathrm{X}$ & & $\mathrm{X}$ & & & $\mathrm{X}$ & & \\
\hline Chamaesiphon amethystinus & & & & $\mathrm{X}$ & & & & & & & & & & \\
\hline
\end{tabular}


continuation

\begin{tabular}{|c|c|c|c|c|c|c|c|c|c|c|c|c|c|}
\hline \multirow{2}{*}{ Species } & \multicolumn{7}{|c|}{ Casamento lagoon area } & \multicolumn{6}{|c|}{ Tapes city area } \\
\hline & WCC & CIL & CML & $\mathrm{GW}$ & BG & SP & PAW & CAL DL & DW & CTL & SML & RL & $\mathrm{AR}$ \\
\hline Chroococcus dispersus & & $\mathrm{X}$ & & & & & & & & & & $\mathrm{X}$ & \\
\hline C. distans & & $\mathrm{X}$ & $\mathrm{X}$ & $\mathrm{X}$ & & & & & & & & & \\
\hline C. limneticus & & $X$ & $\mathrm{X}$ & $X$ & & $\mathrm{X}$ & & & & & & & \\
\hline C. microscopicus & & $\mathrm{X}$ & & & & & & & & & & & \\
\hline C. minimus & & & & & & $\mathrm{X}$ & & & & $\mathrm{X}$ & & & \\
\hline C. minutus & & & $\mathrm{X}$ & & & & & & & & & & \\
\hline C. turgidus & $X$ & & & & & & & & & $\mathrm{X}$ & & $\mathrm{X}$ & \\
\hline Coelomoron pusillum & & & & $\mathrm{X}$ & & & & & & & & & \\
\hline $\begin{array}{c}\text { Coelosphaerium } \\
\text { kuetzingianum }\end{array}$ & & & & & & & $\mathrm{X}$ & & & & & & \\
\hline Cyanodictyon reticulatum & & & $\mathrm{X}$ & & $\mathrm{X}$ & $\mathrm{X}$ & & & & & & & \\
\hline C. tubiforme & & & $\mathrm{X}$ & & & $\mathrm{X}$ & $\mathrm{X}$ & & & & & & \\
\hline M. glauca & & & & $\mathrm{X}$ & & & & $\mathrm{X}$ & $\mathrm{X}$ & $\mathrm{X}$ & $\mathrm{X}$ & $\mathrm{X}$ & $\mathrm{X}$ \\
\hline M. punctata & & & & & & & $\mathrm{X}$ & & & $\mathrm{X}$ & & & \\
\hline M. tenuissima & & & & $\mathrm{X}$ & & $\mathrm{X}$ & & & & & & & \\
\hline Microcrocis pulchella & & & $\mathrm{X}$ & $\mathrm{X}$ & & & & & & & & & \\
\hline Microcystis aeruginosa & $\mathrm{X}$ & $\mathrm{X}$ & $\mathrm{X}$ & $\mathrm{X}$ & & $\mathrm{X}$ & & & & & & & \\
\hline M. protocystis & & & $\mathrm{X}$ & & & & & & & & & $\mathrm{X}$ & \\
\hline M. smithii & & & & & & & & & & $\mathrm{X}$ & & & \\
\hline M. wesenbergii & & & $\mathrm{X}$ & & & & & & & & & & \\
\hline Snowella lacustris & & & $\mathrm{X}$ & & & $\mathrm{X}$ & & & & & & & \\
\hline
\end{tabular}

\section{RESULTS AND DISCUSSION}

Thirty one species of coccoid cyanobacteria belonging to orders Synechococcales (20 species) and
Chroococcales (11 species) were found in the aquatic environments sampled (table 2).

Order Synechococcales

1. Cells sessile

Chamaesiphon amethystinus

1. Cells not sessile 2

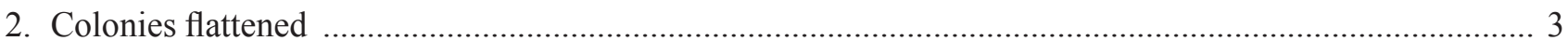

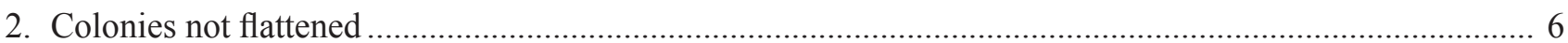

3. Cells irregularly arranged .......................................................................................... Microcrocis pulchella

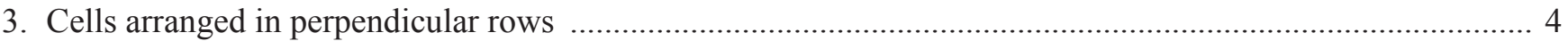

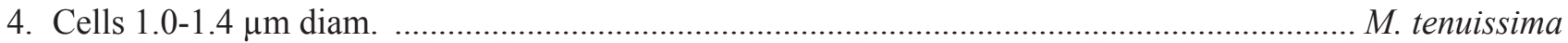

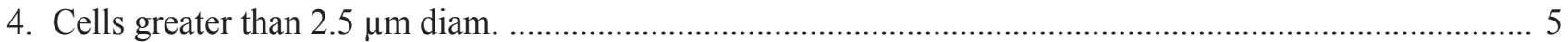

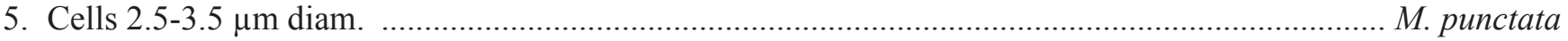

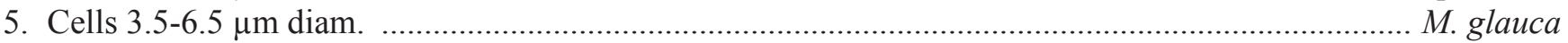

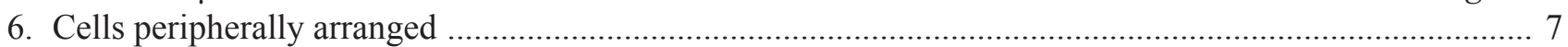

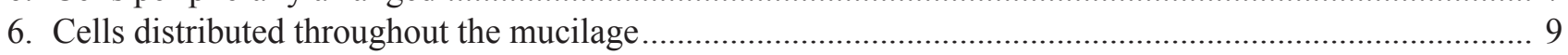

7. Cells with central stalk system ................................................................................................ Snowella lacustris

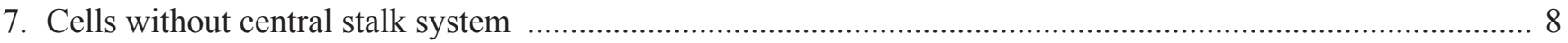

8. Cells oval ........................................................................................................... Coelomoron pusillum

8. Cells spherical or hemispherical ....................................................... Coelosphaerium kuetzinginanum

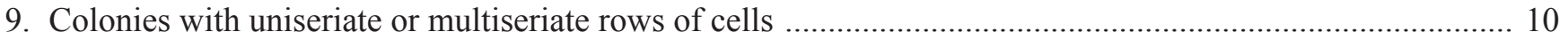

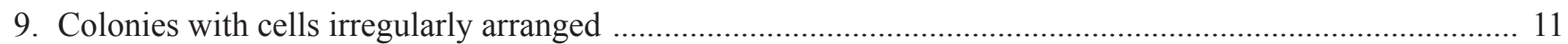
10. Cells spherical Cyanodictyon reticulatum 10. Cells oval or elongated C. tubiforme 


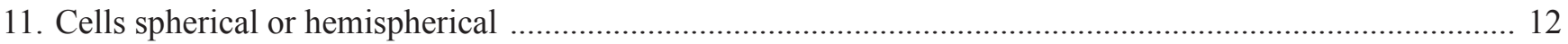

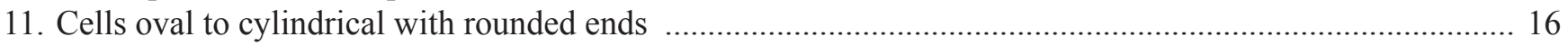

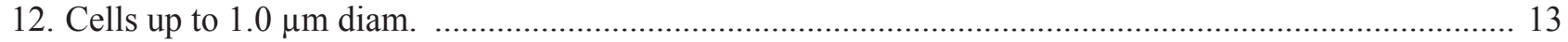

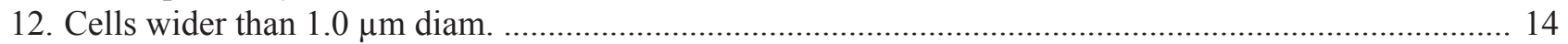

13. Cells sparsely arranged in mucilage ................................................................... Aphanocapsa delicatissima

13. Cells densely arranged in mucilage ......................................................................................... A. holsatica

14. Cells densely arranged in central region of colony ................................................................ A. incerta

14. Cells sparsely and irregularly arranged in mucilage .................................................................. 15

15. Cells 2.0-3.0

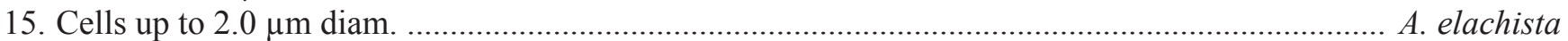

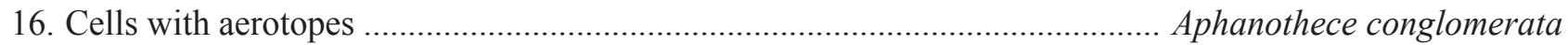

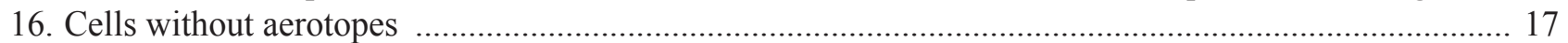

17. Cells densely arranged in central region of colony .......................................................................... A. comasii

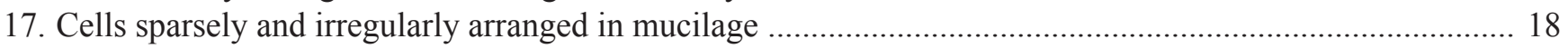

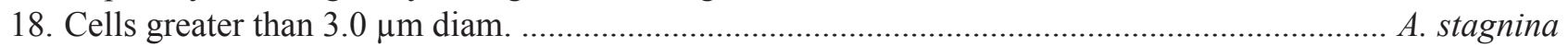

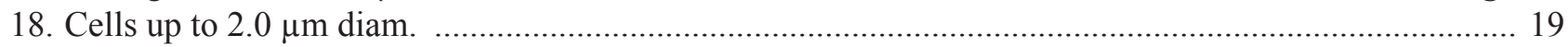

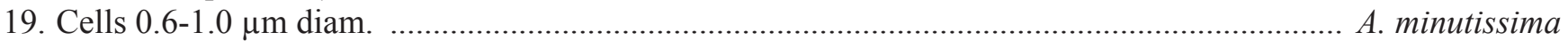

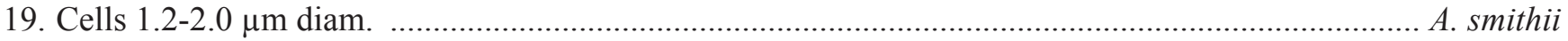

\section{SYNECHOCOCCACEAE}

Aphanothece comasii Komárková-Legnerová \& Tavera, Algolog. Stud. 83: 408, 1996.

Figures 2, 34

Colonies microscopic, spherical or oval, 20.0$37.0 \mu \mathrm{m}$ diam., 30.0-49.0 $\mu \mathrm{m}$ long; cells densely and irregularly distributed in the central part of colony; mucilage homogenous, colorless, conspicuous margin; cells oval, 1.8-3.0 $\mu \mathrm{m}$ diam., 2.7-4.0 $\mu \mathrm{m}$ long; cell contents blue-green, homogenous or granulated.

Material examined: BRAZIL. Rio GRANDE DE Sul: Palmares do Sul, Gateados wetland, 7-V-2003, VRWerner s.n. (HAS104131, HAS104132); Gateados lagoon, 19-XI-2003, LSCardoso s.n. (HAS104376).

Comments: Most of the population was formed by small colonies that had cells densely arranged within the central region of the colonial mucilage. The older cells of the colonies were sparsely arranged.

Aphanothece conglomerata Rich, Trans. R. Soc. S. Afr. 20: 185, 1932.

Figure 3

Colonies microscopic, elongated or irregular, 28.5$78.0 \mu \mathrm{m}$ diam., 80.0-213.0 $\mu \mathrm{m}$ long; cells loosely and irregularly arranged within the colonial mucilage; mucilage, homogenous, colorless rarely lamellate, conspicuous margin (rarely inconspicuous); cells oval, 3.0-3.5 $\mu \mathrm{m}$ diam., 4.0-5.8 $\mu \mathrm{m}$ long; cell contents bluegreen, with or without granules; with aerotopes.
Material examined: BRAZIL. Rio GRANDE DE Sul: Palmares do Sul, Gateados lagoon, 9-V-2003, VRWerner s.n. (HAS104174).

Comments: Most of the population had aggregate colonies that were arranged within a common mucilage. This feature was also observed in A. elebans (Brébisson) Elenkin. However, A. elebans is known from temperate zones and has small cells (1-2(-3) $\mu \mathrm{m}$ diam. $\times 2.8-6.5 \mu \mathrm{m}$ long), while $A$. conglomerata is known from tropical and subtropical zones (Komárek \& Anagnostidis 1998).

Aphanothece minutissima W. West, Proc. R. Ir. Acad.31: 35, 1912.

Figure 4

Colonies microscopic, spherical, elongated or irregular, 45.0-60.0 $\mu \mathrm{m}$ diam., 54.0-96.6 $\mu \mathrm{m}$ long; cells loosely and irregularly arranged within the colonial mucilage; mucilage homogenous, colorless, diffluent margin; cells oval to cylindrical with rounded ends, 0.6-1.0 $\mu \mathrm{m}$ diam., 1.3-1.8 $\mu \mathrm{m}$ long; cell contents bluegreen, homogenous.

Material examined: BRAZIL. Rio GRANDE do SuL: Capivari do Sul, Capivari lagoon, 5-V-2003, LCTorgan s.n. (HAS104098, HAS104343); Tapes, Charutão lagoon, 3-VI-2003, VRWerner s.n. (HAS104202); Palmares do Sul, Rincão do Anastácio wetland, 28-X-2003, SMAlvesda-Silva s.n. (HAS104369); Casamento lagoon, 18-XI2003, LSCardoso s.n. (HAS104352).

Comments: Aphanothece pulverulenta Bachman, A. nebulosa Skuja, and A. minutissima are very similar. According to Komárková-Legnerová \& Cronberg 


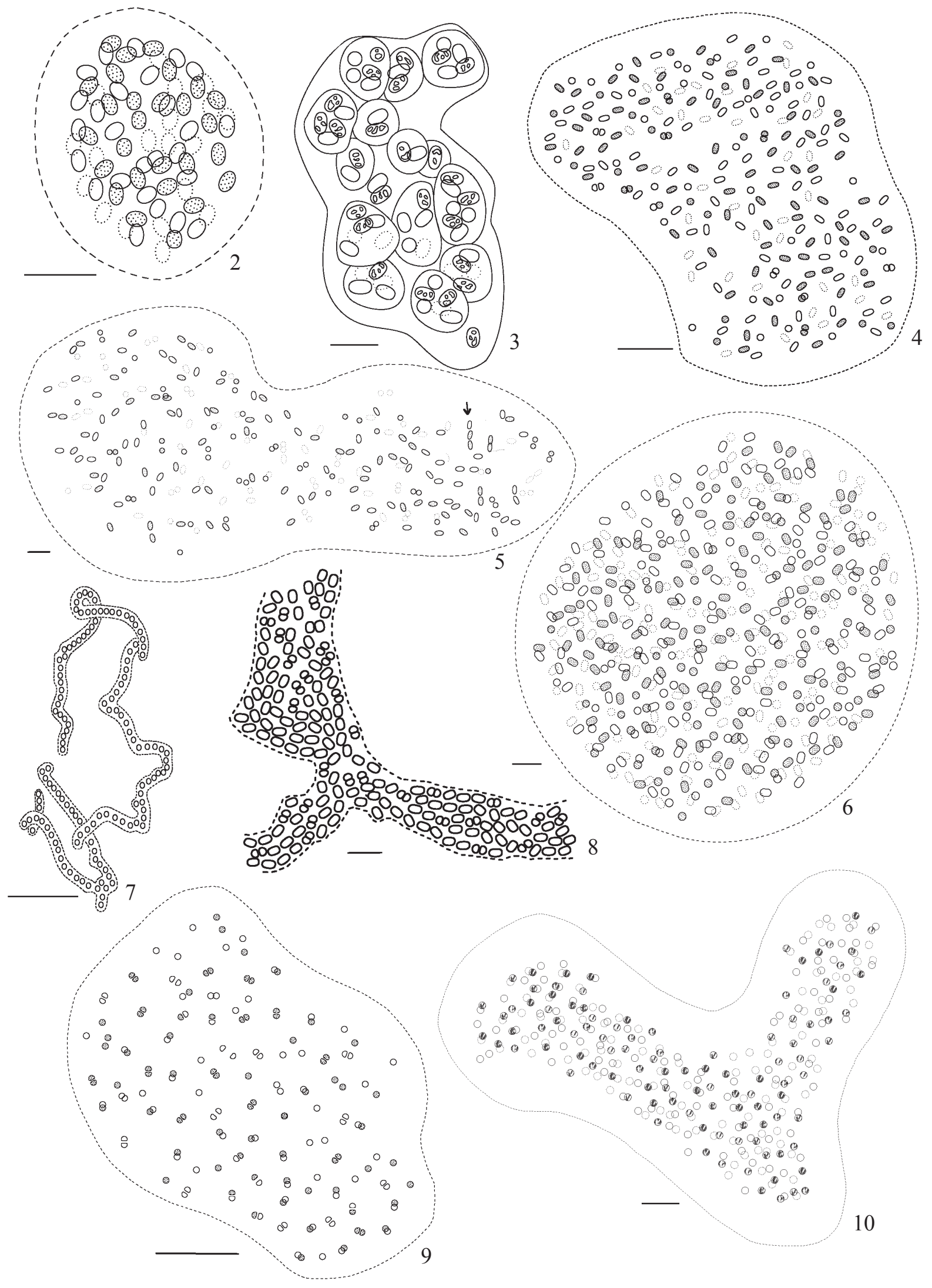

Figures 2-10. 2. Aphanothece comasii. 3. A. conglomerata. 4. A. minutissima. 5. A. smithii (arrow: cells in rows). 6. A. stagnina. 7. Cyanodictyon reticulatum. 8. C. tubiforme. 9. Aphanocapsa delicatissima. 10. A. elachista. Bar $=10 \mu \mathrm{m}$. 
(1994), these three species may belong to A. minutissima. However, Komárek \& Anagnostidis (1998) consider $A$. pulverulenta and $A$. minutissima synonymous, with A. nebulosa being a distinct species because it has smaller cells.

Aphanthece smithii Komárková-Legnerová \& Cronberg, Algolog. Stud. 72: 25, 1994.

Figures 5, 35

Colonies microscopic, spherical, oval, elongated, or irregular, 52.5-108.6 $\mu \mathrm{m}$ diam., 62.9-221.8 $\mu \mathrm{m}$ long; cells loosely and irregularly arranged within the colonial mucilage; mucilage homogenous, colorless, diffluent margin; cells oval to cylindrical with rounded ends, 1.2$2.0 \mu \mathrm{m}$ diam., 1.7-2.9 $\mu \mathrm{m}$ long; cell contents blue-green, homogenous; rare and minute aerotopes.

Material examined: BRAZIL. Rio GRANDE Do SUL: Palmares do Sul, Rincão do Anastácio wetland 7-V-2005, VRWerner s.n. (HAS104124); Capivari lagoon, 18-XI2003, LSCardoso s.n. (HAS104343); Casamento lagoon, 18-XI-2003, LSCardoso s.n. (HAS104351, HAS104352); Tapes, Charutão lagoon, 3-VI-2003, LCTorgan s.n. (HAS104195, HAS104202), 2-XII-2003, LSCardoso s.n. (HAS104420, HAS104425); Dunas lagoon, 4-VI-2003, VRWerner s.n. (HAS104230), 3-XII-2003, LSCardoso s.n. (HAS104442).

Comments: The populations studied showed wider variations of their cell dimensions than the maximum specified by Komárková-Legnerová \& Cronberg (1994). However, other features were according to the species diagnosis. Colony size and shape were variable, and the elongated colonies showed cells arranged in simple rows, like Cyanodictyon tubiforme Cronberg (figure 4).

Aphanothece stagnina (Sprengel) Braun, In: Rabenhorst, Flora Eur. Algar. 157: 1572, 1863.

Figures 6, 36

Colonies microscopic, spherical, elongated or irregular, 35.0-125.0 $\mu \mathrm{m}$ diam., 63.0-247.5 $\mu \mathrm{m}$ long; cells loosely and irregularly arranged within the colonial mucilage; mucilage homogenous, colorless, diffluent margin (rarely conspicuous); cells oval to cylindrical with rounded ends, sometimes with their own colorless gelatinous envelopes, 4.0-6.0 $\mu \mathrm{m}$ diam., 6.0-9.0 $\mu \mathrm{m}$ long; cell contents blue-green, homogenous.

Material examined: BRAZIL. RIO GRANDE DO Sul: Palmares do Sul, Rincão do Anastácio wetland, 7-V-2003, VRWerner s.n. (HAS104124); Gateados wetland, 8-V-2003, VRWerner s.n. (HAS104134); Mostardas, Gateados lagoon, 8-V-2003, LCTorgan s.n.
(HAS104147), 9-V-2003, VRWerner s.n. (HAS104174); Tapes, São Miguel lagoon, 4-VI-2003, VRWerner s.n. (HAS104203); Dunas lagoon, 4-VI-2003, VRWerner s.n. (HAS104230).

Comments: Although A. stagnina is known to be benthic and to form a macroscopic thallus, it can occasionally be found in the plankton; there are records (Komárková-Legnerová \& Cronberg 1994, Werner 1988, 2002, Franceschini 1992, Joosten 2006) of this species forming microscopic thalli, as was observed in the present study. According to Komárek \& Kastovsky (2003) and Komárek (2006), A. stagnina is phylogenetically distinct from Synechococcaceae and belongs to Cyanobacteriaceae (Hoffmann et al. 2005).

Cyanodictyon reticulatum (Lemmermann) Geitler, In: Pascher, Süßw. Fl. Heft. 12: 103, 1925.

Figures 7, 37

Colonies microscopic, more or less spherical, or slightly elongated to irregular, 12.0-33.0 $\mu \mathrm{m}$ diam., 24.0$47.5 \mu \mathrm{m}$ long; cells arranged in simple gelatinous rows, forming reticulate colonies; mucilage homogenous, colorless, conspicuous margin; cells spherical, 0.9$1.4 \mu \mathrm{m}$ diam.; cell contents blue-green, homogenous.

Material examined: BRAZIL. Rio GRANDE DE Sul: Palmares do Sul, Casamento lagoon, 5-V-2003 VRWerner s.n. (HAS104103, HAS104117), 7-V-2003, LCTorgan s.n. (HAS104106), 18-XI-2003, LSCardoso s.n. (HAS104351, HAS104352); Spillway 7-V-2003, LCTorgan s.n. (HAS104163, HAS104167), 18-XI-2003, LSCardoso s.n. (HAS104381); Gateados wetland, 7-V-2003, VRWerner s.n. (HAS104131, HAS104132); Capivari lagoon, 18XI-2003, LSCardoso s.n. (HAS104343).

Cyanodictyon tubiforme Cronberg, Arch. Hydrobiol. 80: 193, 1988.

Figures 8, 38-39

Colonies microscopic, elongated or irregular, sometimes clathrate, up to $326.0 \mu \mathrm{m}$ long; cells arranged in multicellular rows in colony; mucilage homogenous, colorless, diffluent margin; cells oval, elongated, hemispherical after division, 2.0-2.4 $\mu \mathrm{m}$ diam., 2.0$2.9 \mu \mathrm{m}$ long; cell contents blue-green, homogenous.

Material examined: BRAZIL. Rio Grande Do Sul: Palmares do Sul, Casamento lagoon, 5-V-2003, VRWerner s.n. (HAS104103, HAS104106); Rincão do Anastácio wetland, 7-V-2003, VRWerner s.n. (HAS104119); Spillway, 7-V-2003, VRWerner s.n. (HAS104167).

Comments: Probably the first citation for Rio Grande do Sul State since no prior reference was found. 


\section{MERISMOPEDIACEAE}

Aphanocapsa delicatissima W. \& G. S. West, J. Limn. Soc. (Bot.) 40: 431, 1912.

Figure 9

Colonies microscopic, spherical, oval or elongated, 13.6-78.7 $\mu \mathrm{m}$ diam., 29.6-168.7 $\mu \mathrm{m}$ long; cells loosely and irregularly arranged within the colonial mucilage; mucilage homogenous, fine, colorless, diffluent margin; cells spherical, hemispherical after division, 0.8-1.0 $\mu \mathrm{m}$ diam.; cell contents blue-green, homogenous.

Material examined: BRAZIL. RIO GRANDE DO SUL: Palmares do Sul, Gateados wetland, 7-V-2003, VRWerner s.n. (HAS104132); Casamento lagoon, 18-XI-2003, LSCardoso s.n. (HAS104352); Tapes, Redonda lagoon, 4-VI-2003, VRWerner s.n. (HAS104235).

Comments: Aphanocapsa delicatissima is very similar to A. elachista W. West et G. S. West, although A. elachista has larger cells than A. delicatissima.

Aphanocapsa elachista (W. \& G. S. West), J. Linn. Soc. Bot., 30: 276, 1894.

Figure 10, 40

Colonies microscopic, spherical, oval, elongated or irregular, 55.0-97.5 $\mu \mathrm{m}$ diam., 60.0-350.0 $\mu \mathrm{m}$ long; cells loosely and irregularly arranged within the colonial mucilage; mucilage homogenous, fine, colorless, diffluent margin; cells spherical, hemispherical after division, 1.5$2.0 \mu \mathrm{m}$ diam.; cell contents blue-green, homogenous.

Material examined: BRAZIL. Rio Grande Do Sul: Palmares do Sul, Gateados wetland, 7-V-2003, VRWerner s.n. (HAS104132); Casamento lagoon, 18-XI-2003, LSCardoso s.n. (HAS104352); Tapes, Redonda lagoon, 4-VI-2003, VRWerner s.n. (HAS104235).

Comments: The taxonomy of planktic Aphanocapsa species or unclear. The morphologies of the species are very simple, differing by their cell dimensions, and by the cell organization in the colony. Aphanocapsa elachista is very similar to $A$. koordersii, as both develop microscopic colonies with more or less sparsely distributed cells within a fine and colorless slime. As A. elachista has smaller cells than $A$. koordersii (Komárková-Legnerová \& Cronberg 1994, Komárek \& Anagnostidis 1998), these two species can be separated by cell size.

Aphanocapsa holsatica (Lemmermann) Cronberg \& Komárek, Algolog. Stud. 75: 327, 1994.

Figure 11

Colonies microscopic, elongated or irregular, 42.3$53.8 \mu \mathrm{m}$ diam., 55.0-215.6 $\mu \mathrm{m}$ long; cells densely and irregularly arranged within the colonial mucilage; mucilage homogenous, fine, colorless, diffluent margin; cells spherical, 0.8-1.0 $\mu \mathrm{m}$ diam.; cell contents bluegreen, homogenous.

Material examined: BRAZIL. RIO GRANDE DO Sul: Palmares do Sul, Casamento lagoon, 7-V-2003, LCTorgan s.n. (HAS104106); Spillway, 7-V-2003, LCTorgan s.n. (HAS104163).

Aphanocapsa incerta (Lemmermann) Cronberg \& Komárek, Algolog. Stud. 75: 327, 1994.

Figures 12, 41

Colonies microscopic, spherical or oval, 40.0$52.0 \mu \mathrm{m}$ diam., 42.0-64.5 $\mu \mathrm{m}$ long; cells densely and irregularly arranged in the central area of the colonial mucilage; mucilage homogenous, fine, colorless, diffluent margin; cells spherical, 1.0-1.5 $\mu \mathrm{m}$ diam.; cell contents blue-green, homogenous.

Material examined: BRAZIL. Rio GRANDE DO Sul: Palmares do Sul, Casamento lagoon, 18-XI-2003, LSCardoso s.n. (HAS104351, HAS104352).

Comments: Aphanocapsa incerta is very similar to A. delicatissima and to A. holsatica, and all three species have small cells. They can be separate by colony morphology or by cell arrangement, with $A$. incerta having spherical colonies and cells densely arranged in central area, A. delicatissima has cells sparsely arranged in the colonial mucilage, and $A$. holsatica forms elongated or irregular colonies.

Aphanocapsa koordersii Ström, Nyt. Mag. Naturv. 61: 128, 1923.

Figures 13, 42

Colonies microscopic, spherical or oval, 49.0$219.0 \mu \mathrm{m}$ diam., $68.7-254.2 \mu \mathrm{m}$ long; cells loosely and irregularly arranged within the colonial mucilage; mucilage homogenous, fine, colorless, diffluent margin; cells spherical, hemispherical after division, 2.0-3.0 $\mu \mathrm{m}$ diam.; cell contents blue-green, homogenous.

Material examined: BRAZIL. Rio GRANDE DO SUL: Palmares do Sul, Rincão do Anastácio wetland 7-V-2003, VRWerner s.n. (HAS104118, HAS104124); Capivari lagoon, 18-XI-2003, LSCardoso s.n. (HAS104343); Casamento lagoon, 18-XI-2003, LSCardoso s.n. (HAS104352), 19-XI-2003, LSCardosos.n.(HAS104356, HAS104369); Gateados lagoon, 19-XI-2003, LSCardoso s.n. (HAS104376); Spillway, 19-XI-2003, LSCardoso s.n. (HAS104381); Tapes, Charutão lagoon, 3-VI-2003, VRWerner s.n. (HAS104195, HAS104202), 2-XII-2003, LSCardoso s.n. (HAS104420); São Miguel lagoon, 

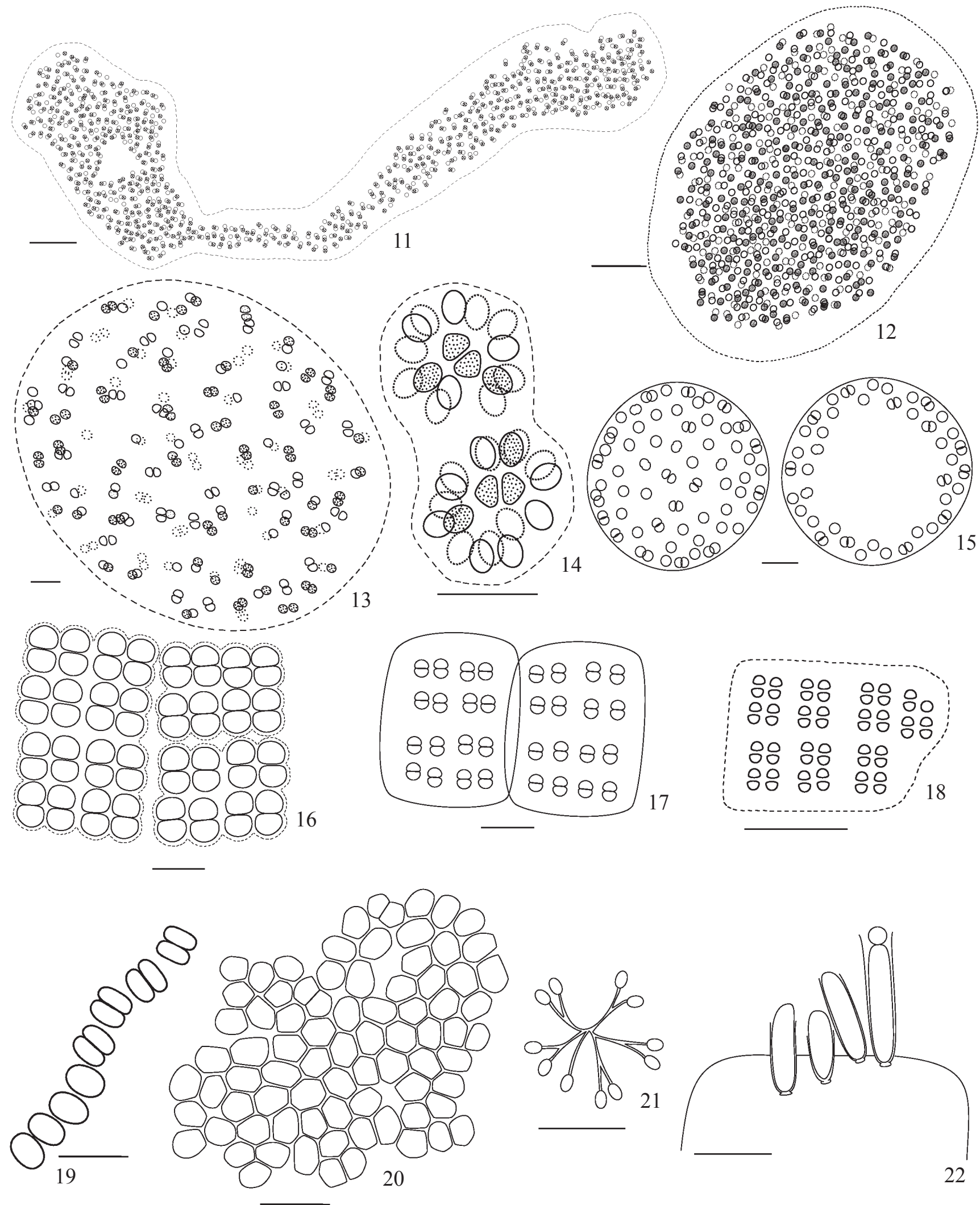

Figures 11-22. 11. Aphanocapsa holsatica. 12. A. incerta. 13. A. koordersii. 14. Merismopedia glauca. 15. M. punctata. 16. M. tenuissima. 17. Microcrocis pulchella (lateral view). 18. M. pulchella (apical view). 19. Coelomoron pusillum. 20. Coelosphaerium kuetzingianum. 21. Snowella lacustris. 22. Chamaesiphon amethystinus. Bar $=10 \mu \mathrm{m}$. 
4-VI-2003, LCTorgan s.n. (HAS104203); Dunas lagoon, 3-XII-2003, LSCardoso s.n. (HAS104442).

Comments: Cells remain close after cell division, with tetrads frequently being observed. Aphanocapsa koordersii is similar to A. elachista and to A. planctonica G. M. Smith. It differs from $A$. elachista only in cell size. The difference between $A$. koordersii and $A$. planctonica is that the former is known from tropical and subtropical regions, while the latter is only known from temperate zones.

Coelomoron pusillum (Van Goor) Komárek \& Hindák, Algolog. Stud. 50-53: 210, 1988.

Figures 14

Colonies microscopic, spherical or slightly oval, 14.5$18.8 \mu \mathrm{m}$ diam.; cells more or less radially arranged along the periphery of the colonial mucilage; mucilage homogenous, colorless, and diffluent; cells oval, 2.2-4.0 $\mu \mathrm{m}$ diam., 3.2$4.5 \mu \mathrm{m}$ long; cell contents blue-green, homogenous.

Material examined: BRAZIL. Rio GRANDE Do SUL: Mostardas, Gateados lagoon, 9-V-2003, VRWerner s.n. (HAS104171).

Comments: Coelomoron pusillum was originally described as belonging to the genus Coelosphaerium, but was later transferred to Coelomoron by Komárek \& Hindák (1988) based on cell shape. This species is widely distributed. Coelomoron tropicale Senna, Peres \& Komárek and C. microcystoides Komárek are similar to C. pusillum, but differ in terms of colony sizes and by cell distributions. Coelomoron tropicale has cells densely and radially gathered in the colonial mucilage, while the cells of $C$. pusillum are slightly distant and not oriented with respect to one another. Coelomoron microcystoides forms larger colonies than C. pusillum (Senna et al. 1998). Probably the first citation for Rio Grande do Sul since no prior reference was found.

Coelosphaerium kuetzingianum Nägeli, Gatt. Einzell. Alg. 54, 1849.

Figure 15

Colonies microscopic, spherical, 50.0$61.5 \mu \mathrm{m}$ diam.; cells loosely and irregularly arranged near the colony surface; mucilage homogenous, fine, colorless, diffluent margin; cells spherical, hemispherical after division, 2.3-2.9 $\mu \mathrm{m}$ diam.; cell contents bluegreen, homogenous or granular.

Material examined: BRAZIL. Rio GRANDE Do SUL: Tapes, Charutão lagoon, 4-VI-2003, LCTorgan s.n. (HAS104202); Palmares do Sul, Casamento lagoon, 19-XI-2003, LSCardoso s.n. (HAS104369).
Comments: Coelosphaerium kuetzingianum and $C$. aerugineum Lemmermann are very similar and commonly misidentified. Coelosphaerium kuetzingianum probably has cosmopolitan occurrence (but very frequent mainly in tropical regions), while C. aerugineum is known from temperate zones (Komárek \& Anagnostidis 1998). Probably the first citation for Rio Grande do Sul since no prior reference was found.

Merismopedia glauca (Ehrenberg) Kützing, Phycol. Germ.142, 1845.

Figures 16, 43

Colonies microscopic, flat, tabular, rectangular, composed of 8-192 cells disposed more or less loosely in perpendicular rows within the colonial mucilage, 20.0-110.0 $\mu \mathrm{m}$ diam., 30.0-165.5 $\mu \mathrm{m}$ long; mucilage homogenous, fine, colorless, diffluent margin; cells spherical, widely oval, hemispherical after division, 3.5$6.5 \mu \mathrm{m}$ diam.; cell contents blue-green, homogenous.

Material examined: BRAZIL. Rio GRANDE Do Sul: Mostardas, Gateados lagoon, 8-V-2003, VRWerner s.n. (HAS104142), 9-V-2003, VRWerner s.n. (HAS104171, HAS104172); Tapes, Charutão lagoon, 3-VI-2003, LCTorgan s.n. (HAS104195, HAS104197, HAS104202), 2-XII-2003, LSCardoso s.n. (HAS104416, HAS104425), 3-XII-2003, LSCardoso s.n. (HAS104450, HAS104451); São Miguel lagoon, 4-VI-2003, VRWerner s.n. (HAS104203), 2-XII-2003, LSCardoso s.n. (HAS104427); Redonda lagoon, 4-VI-2003, VRWerner s.n. (HAS104235, HAS104240); Capivaras lagoon, 3XII-2003, LSCardoso s.n. (HAS104436); Araçá, 3-XII2003, LSCardoso s.n. (HAS104457); Dunas wetland, 3-XII-2003, LSCardoso s.n. (HAS104446).

Comments: The features of the populations observed are consistent with the species diagnosis, except in terms of their cell sizes, which are larger than the maximum value cited by Komárek \& Anagnostidis (1998).

Merismopedia punctata Meyen, Neues Syst. Pfl. Physiol. 3: 440, 1839.

Figure 17

Colonies microscopic, flat, tabular, rectangular, composed by 16-64 cells disposed more or less loosely in perpendicular rows, $15.0-35.0 \mu \mathrm{m}$ diam., 20.0$53.0 \mu \mathrm{m}$ long; mucilage homogenous, fine, colorless, diffluent margin; cells spherical, hemispherical after division, 2,.5-3.5 $\mu \mathrm{m}$ diam.; cell contents blue-green, homogenous.

Material examined: BRAZIL. Rio Grande so Sul: Tapes, Charutão lagoon, 3-VI-2003, VRWerner 
s.n. (HAS104195), 4-VI-2003, LCTorgan s.n. (HAS104197, HAS104202); Palmares do Sul, Rincão do Anastácio wetland, 29-X-2003, SMAlves-da-Silva s.n. (HAS104362).

Comments: Merismopedia punctata is a common species and very similar to $M$. glauca and M. hyalina (Ehrenberg) Kützing. It differs from M. glauca in terms of cell size. Merismopedia punctata can be distinguished from M. hyalina by the smaller numbers of cells in its colonies and by the somewhat irregular cell arrangement in M. hyalina.

Merismopedia tenuissima Lemmermann, Bot. Zbl. 76: 154, 1898.

Figure 18

Colonies microscopic, flat, tabular, quadrate, composed of 16-32 cells disposed more or less densely in perpendicular rows, 14.0-18.5 $\mu \mathrm{m}$ diam., 16.0-20.0 $\mu \mathrm{m}$ long; mucilage homogenous, fine, colorless, diffluent margin; cells spherical, hemispherical after division, 1.0$1.4 \mu \mathrm{m}$ diam.; cell contents blue-green, homogenous.

Material examined: BRAZIL. Rio GRANDE Do Sul: Palmares do Sul, Gateados wetland, 7-V-2003, VRWerner s.n. (HAS104132); Spillway, 7-V-2003, LCTorgan s.n. (HAS104163).

Comments: Merismopedia tenuissima and $M$. africana Komárek \& Cronberg are similar as both have small cells; they can be distinguished by their colony morphology, as $M$. africana always forms arcuate colonies.

Microcrocis pulchella (Buell) Geitler in Engler \& Prantl, Natürl. Planzenfam., 56, 1942.

Figures 19-20, 44

Colonies microscopic, flat, tabular, elongated, and irregular, 40.0-68.5 $\mu \mathrm{m}$ diam., 52.0-102.0 $\mu \mathrm{m}$ long; cells densely and irregularly arranged; mucilage homogenous, colorless, and diffluent; cells polygonal in apical view, elongated or oval at the periphery of the colonial mucilage, becoming hemispherical after division, spherical, 3.0-4.0 $\mu \mathrm{m}$ diam., 4.4-5.2 $\mu \mathrm{m}$ long; cells elongated in lateral view, 4.0-4.8 $\mu \mathrm{m}$ long; cell contents blue-green, homogenous.

Material examined: BRAZIL. Rio GRANDE DO SuL: Mostardas, Gateados lagoon, 9-V-2003, VRWerner s.n. (HAS104171); Palmares do Sul, Casamento lagoon, 27X-2003, SMAlves-da-Silva s.n. (HAS104348).

Comments: Microcrocis pulchella was originally described as Holopedia pulchella by Buell (1938) from specimens found growing in the inner region of a cyanobacterial mass. This species is not common but was previously observed in a brackish water zone in southern Brazil by Werner \& Sant'Anna (2006). The species was observed in freshwater in the present study, as originally described (Buell, 1938). The morphologies of the cells and their arrangement in the colonies resemble $M$. granulata (Skuja) Skuja. Nevertheless, M. granulata has wavy or rolling colonial margins, while $M$. pulchella develops flat colonies.

Snowella lacustris (Chodat) Komárek \& Hindák, Algolog. Stud. 50-53: 203, 1988.

Figure 21

Colonies microscopic, spherical or oval, 22.0$45.0 \mu \mathrm{m}$ diam., 23.0-51.0 $\mu \mathrm{m}$ long; mucilage homogenous, colorless, diffluent margin, stalks thin; cells more or less radially arranged at the periphery of the colony; cells obovoid, 1.3-2.5 $\mu \mathrm{m}$ diam., 2.0-3.2 $\mu \mathrm{m}$ long; cell contents blue-green, homogenous.

Material examined: BRAZIL. Rio GRANDE DO Sul: Palmares do Sul, Casamento lagoon, 5-V-2003, VRWerner s.n. (HAS104103), 27-X-2003, SMAlvesda-Silva s.n. (HAS104348), 18-XI-2003, LSCardoso s.n. (HAS104351, HAS104352); Spillway, 7-V-2003, LCTorgan s.n. (HAS104163).

\section{CHAMAESIPHONACEAE}

Chamaesiphon amethystinus (Rostafinski) Lemmermann, Krypt. Fl. Mark Brandenb. 3: 99, 1910.

Figures 22, 45

Cells solitary, or arranged parallel to one another and form groups but each is attached individually to the substrate; sheath hyaline, firm, colorless; cells cylindrical or slightly widening toward the ends, widely rounded at apex, blunt at base, with gelatinous pad, 3.0-4.5 $\mu \mathrm{m}$ diam., 6.4-18.5 $\mu \mathrm{m}$ long; cell contents blue-green, homogenous; exocytes rare, spherical, solitary.

Material examined: BRAZIL. Rio GRANDE Do Sul: Mostardas, Gateados lagoon, 9-V-2003, VRWerner s.n. (HAS104171).

Comments: The population studied was similar in its morphology and size to Chamaesiphon incrustans Grunow. Nevertheless, the specimens showed a distinct and gelatinous pad that assisted in its adherence, while C. incrustans does not have any such adhering disk (Komárek \& Anagnostidis 1998). The exocytes, rarely observed, were spherical and solitary. Probably the first citation for Rio Grande do Sul State since no prior reference was found. 
Order Chroococcales

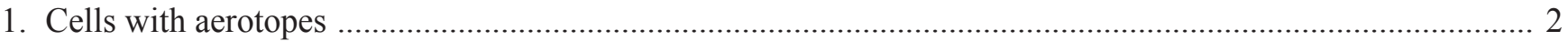

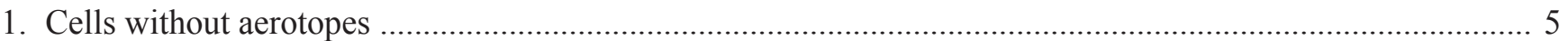

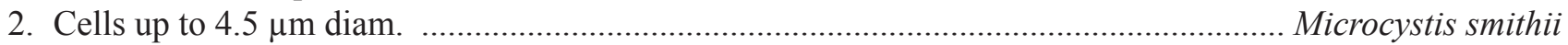

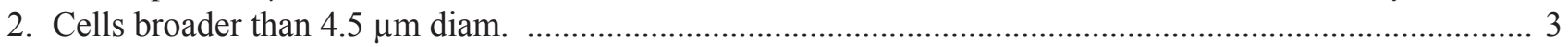

3. Colonies enveloped by a distinctly delimited mucilage, usually slightly refractive on the margins, lobate colonies M. wesenbergii

3. Colonies enveloped by diffluent, sometimes indistinct slime, colonies not lobate

4. Colonies with densely distributed cells M. aeruginosa

4. Colonies with sparsely arranged cells M. protocystis

5. Cells solitary or in small groups (2-4 cells) 6

5. Cells forming colonies with more than 8 cells

6. Cells up to $7.5 \mu \mathrm{m}$ diam. 7

6. Cells broader than $8.0 \mu \mathrm{m}$ diam. Chroococcus minutus

7. Cells up to $1.1 \mu \mathrm{m}$ diam. C. turgidus

7. Cells more than $1.1 \mu \mathrm{m}$ diam. C. microscopicus

8. Cells up to $4.5 \mu \mathrm{m}$ diam. 8

8. Cells larger than $5.3 \mu \mathrm{m}$ diam. 9

9. Cells remain in groups after division, irregularly distributed, cells $3.0-4.5 \mu \mathrm{m}$ diam. 10

9. Cells separate after division, usually distant one from another, cells 2.4-3.0 $\mu \mathrm{m}$ diam. 10. Cells 5.3-7.5 $\mu \mathrm{m}$ diam., without individual envelopes around cells dispersus 10. Cells 6.0-10.5 $\mu \mathrm{m}$ diam., with narrow individual envelopes around cells C. minimus C. distans C. limneticus

\section{MICROCYSTACEAE}

Microcystis aeruginosa (Kützing) Kützing, Tab. Phycol. 1: $6,1846$.

Figures 23, 46

Colonies mucilaginous, microscopic, irregular, usually elongated, lobate, sometimes clathrate, 45.0$127.0 \mu \mathrm{m}$ diam., $68.0-335.0 \mu \mathrm{m}$ long; irregularly and densely arranged cells in the central part of the colonial mucilage; mucilage colorless, structureless, diffluent, sometimes forming a wide margin; cells spherical, sometimes slightly elongated, 4.5-6.5 $\mu \mathrm{m}$ diam.; cell contents blue-green; with aerotopes.

Material examined: BRAZIL, Rio GRANDE Do Sul: Palmares do Sul, Casamento lagoon, 5-V-2003, VRWerner s.n. (HAS104106), 28-X-2003, SMAlves-da-Silva s.n. (HAS104370, HAS104396); Spillway, 7-V-2003, LCTorgan s.n. (HAS104167), 18-XI-2003, LSCardoso s.n. (HAS104351); Capivari lagoon, 18-XI-2003, LSCardoso s.n. (HAS104343); Mostardas, Gateados lagoon, 8-V-2003, VRWerner s.n. (HAS104142), 19XI-2003, LSCardoso s.n. (HAS104372, HAS104376), 20-XI-2003, LSCardoso s.n. (HAS104399); Capivari do Sul, Capivari/Casamento wetland, 27-X-2003, SMAlvesda-Silva s.n. (HAS104339).

Comments: Microcystis aeruginosa is the most widespread species in Brazil (Sant'Anna \&
Azevedo 2000), but misidentifications have probably contributed to its presumed distribution (Sant'Anna et al. 2004).

Microcystis protocystis Crow, New Phytol. 22(2): 62, 1923.

Figures 24, 47

Colonies mucilaginous, microscopic, irregular, spherical or elongated, 125.0-305.0 $\mu \mathrm{m}$ diam., 150.0$434.0 \mu \mathrm{m}$ long; cells irregularly and sparsely arranged within the colonial mucilage; mucilage colorless, structureless, diffluent; cells spherical, sometimes with their own colorless gelatinous envelopes, 4.5-6.5 $\mu \mathrm{m}$ diam.; cell contents blue-green; with aerotopes.

Material examined: BRAZIL. Rio GRANDE DO Sul: Palmares do Sul, Casamento lagoon, 5-V-2003, LCTorgan s.n. (HAS104106), 19-XI-2003, LSCardoso s.n. (HAS104369); Tapes, Charutão lagoon, 3-XII-2003, LSCardoso s.n. (HAS104451).

Comments: a mucilaginous envelope around each cell makes Microcystis protocystis distinct from other Microcystis species, although not all colonies had cells with individual envelopes. Cell sizes of $M$. protocystis and $M$. aeruginosa are similar, but these species can be distinguished by the different arrangements of the cells within their colonies. 


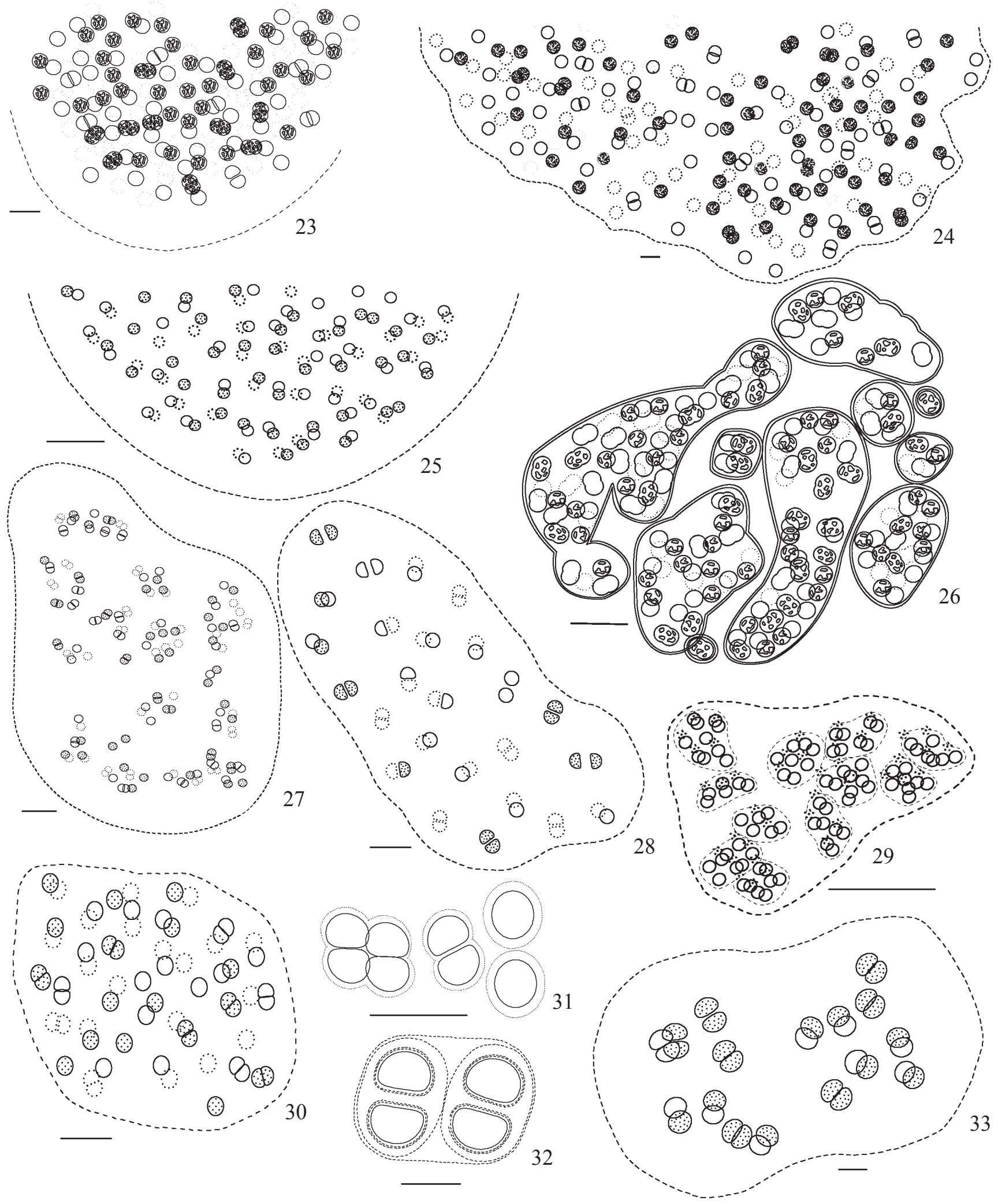

Figures 23-33. 23. Microcystis aeruginosa. 24. M. protocystis. 25. M. smithii. 26. M. wesenbergii. 27. Chroococcus dispersus. 28. C. microscopicus. 29. C. distans. 30. C. minimus. 31. C. minutus. 32. C. turgidus. 33. Limnococcus limneticus. Bar $=10 \mu \mathrm{m}$. 
Microcystis smithii Komárek \& Anagnostidis, Preslia, 67: 21, 1995.

Figures 25, 48-49

Colonies mucilaginous, microscopic, spherical, oval or elongated, 80.0-150.0 $\mu \mathrm{m}$ diam., 93.0-357.0 $\mu \mathrm{m}$ long; cells irregularly and sparsely arranged within the colonial mucilage; mucilage colorless, structureless, diffluent; cells spherical, single or in pairs after division, 3.5$4.5 \mu \mathrm{m}$ diam.; cell contents blue-green, with one or several aerotopes in each cell.

Material examined: BRAZIL. Rio GRANDE Do SUL: Tapes, Charutão lagoon, 3-VI-2003, VRWerner s.n. (HAS104195).

Comments: As many cells are arranged in pairs within the colonial mucilage, $M$. smithii appears similar to Aphanocapsa species. Nevertheless, the presence of aerotopes in the cells allows differenciation and correct classification of the Microcystis genus.

Microcystis wesenbergii (Komárek) Komárek In Kondrateva, Cvetenie vody, 32, 1968.

Figures 26, 50

Colonies microscopic, 20.0-69.0 $\mu \mathrm{m}$ diam., 35.0$157.0 \mu \mathrm{m}$ long, spherical, elongated, lobate, irregular, clathrate, sometimes composed of subcolonies; cells irregularly arranged within the colonial mucilage; mucilage colorless, structureless, with distinctly delimited, firm, continuous, with refractive outline; cells spherical, 5.0-8.0 $\mu \mathrm{m}$ diam.; cell contents blue-green; with aerotopes.

Material examined: BRAZIL. RIO GRANDE DO Sul: Palmares do Sul, Casamento lagoon, 5-V-2003, LCTorgan s.n. (HAS104106).

\section{CHROOCOCCACEAE}

Chroococcus dispersus (Keissler) Lemmermann, Ark. Bot. 2(2): 102, 1904.

Figure 27

Colonies free floating, microscopic, elongated or irregular, 62.5-71.7 $\mu \mathrm{m}$ diam., 80.3-89.7 $\mu \mathrm{m}$ long; cells irregularly arranged, sometimes in groups, which are distant from one other within the colonial mucilage; mucilage colorless, firm, diffluent; cells spherical or hemispherical after division, 3.0-4.5 $\mu \mathrm{m}$ diam.; cell contents blue-green, homogenous.

Material examined: BRAZIL. Rio GRANDE DO Sul: Palmares do Sul, Capivari lagoon, 18-XI-2003, LSCardoso s.n. (HAS104343); Tapes, Charutão lagoon, 3-XII-2003, LSCardoso s.n. (HAS104451).
Comments: Chroococcus dispersus belongs to the group of planktic Chroococcus species. The main distinguishing feature of this species is that the cells are distributed in small groups that remain distant from one another within this the colonial mucilage. It differs from Limnococcus limneticus (Lemmermann) Komárková et al. by its smaller cell dimensions and by having colonies with greater numbers of cells.

Chroococcus distans (G. M. Smith) KomárkováLegnerová \& Cronberg, Algolog. Stud. 72: 26-27, 1994.

Figures 28, 51

Colonies microscopic, elongated or irregular, 55.5-70.8 $\mu \mathrm{m}$ in diameter, 67.3-121.8 $\mu \mathrm{m}$ long; cells irregularly and sparsely arranged within the colonial mucilage; mucilage colorless, firm, homogenous, diffluent; cells 5.3-7.5 $\mu \mathrm{m}$ in diameter, spherical or hemispherical after division, individual envelops lacking; cell contents blue-green, homogenous.

Material examined: BRAZIL. Rio GRANDE Do Sul: Mostardas, Gateados lagoon, 8-V-2003, LCTorgan s.n. (HAS104150); Palmares do Sul, Casamento lagoon, 27X-2003, SMAlves-da-Silva s.n. (HAS104348), 18-XI2003, LSCardoso s.n. (HAS104352); Capivari lagoon, 18-XI-2003, LSCardoso s.n. (HAS104343).

Comments: The cell characteristics of Chroococcus distans and Limnococcus limneticus are similar, but the species can be distinguished by their colony sizes and by the arrangements of the cells within the colonial mucilage. Chroococcus distans forms larger colonies and the cells of older colonies are more distant one from the other.

Chroococcus microscopicus Komárková-Legnerová \& Cronberg, Algolog. Stud. 72: 28, 1994.

Figure 29

Colonies free floating, microscopic, irregular, 5.5$18.5 \mu \mathrm{m}$ diam., 6.5-30.0 $\mu \mathrm{m}$ long; cells forming groups, which are irregularly arranged within the colonial mucilage; mucilage colorless, firm, homogenous, diffluent; cells spherical, 0.8-1.1 $\mu \mathrm{m}$ diam.; cell contents blue-green, homogenous.

Material examined: BRAZIL. Rio GRANDE DO Sul: Palmares do Sul, Capivari lagoon, 18-XI-2003, LSCardoso s.n. (HAS104343).

Comments: Chroococcus microscopicus and $C$. aphanocapsoides Skuja are similar, both having small cells. These two species can be distinguished by their 
cell and colony sizes, where $C$. aphanocapsoides has larger colonies and large cells distributed within a common colonial mucilage, while C. microscopicus has smaller cells that are united into small groups, with each cell being surrounded by an individual mucilaginous sheath.
Chroococcus minimus (Keissler) Lemmermann, Ark. F. Bot. 2: 102, 1904.

Figures 30, 52

Colonies free floating, microscopic, oval, irregular, 30.5-48.3 $\mu \mathrm{m}$ diam., 50.3-63.8 $\mu \mathrm{m}$ long; cells more or
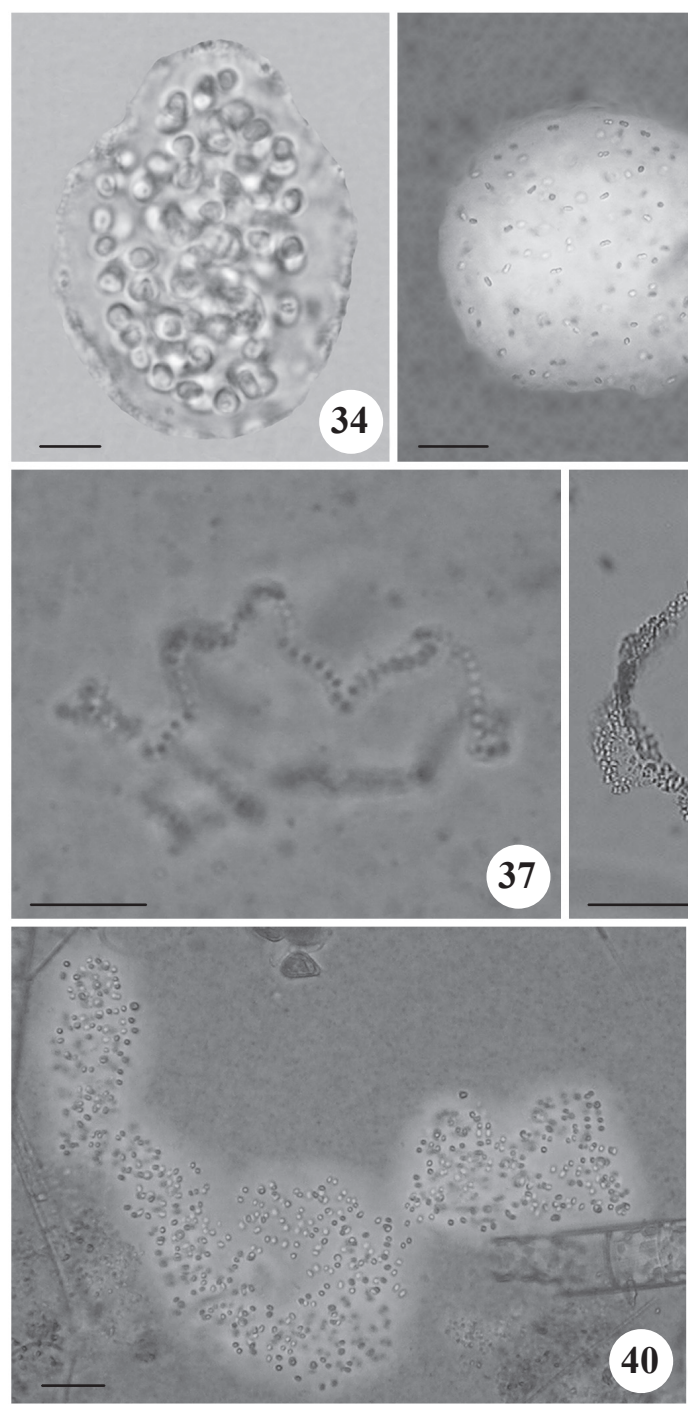

40
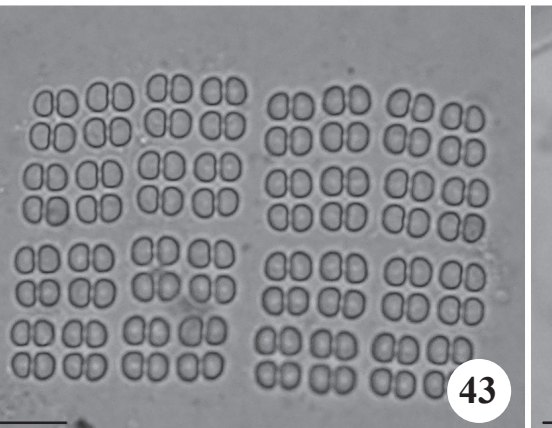

35

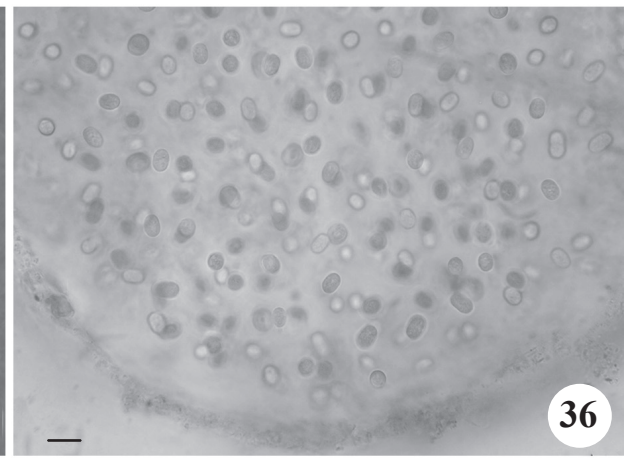

41

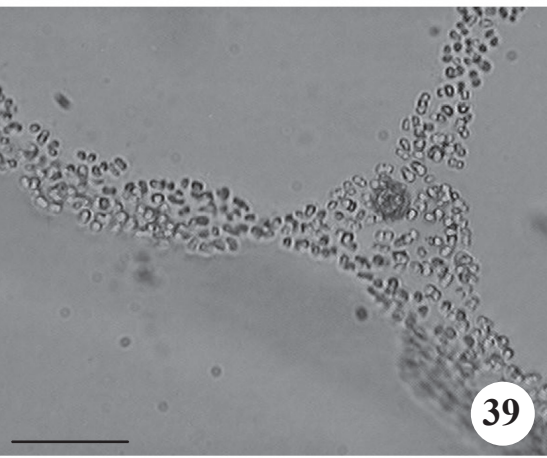

38
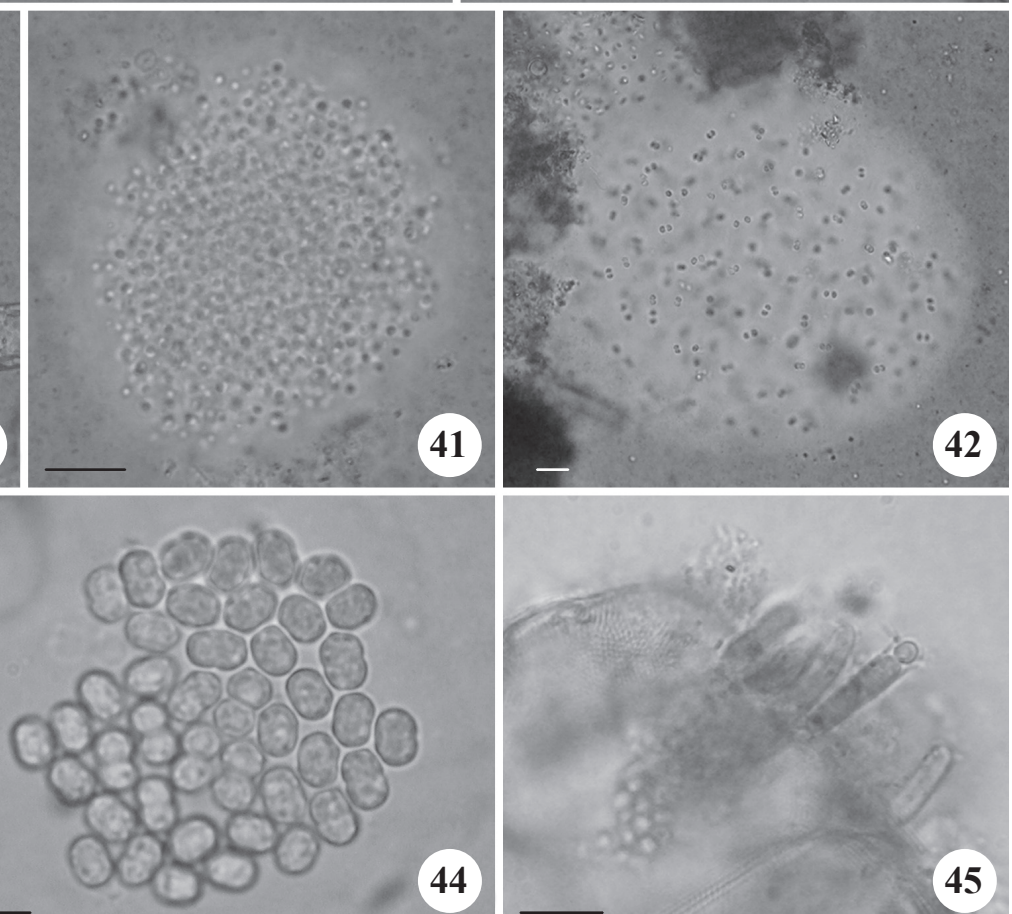

44

Figures 34-45. 34. Aphanothece comasii. 35. A. smithii. 36. A. stagnina. 37. Cyanodictyon reticulatum. 38-39. C. tubiforme. 40. Aphanocapsa elachista. 41. A. incerta. 42. A. koordersii. 43. Merismopedia glauca. 44. Microcrocis pulchella. 45. Chamaesiphon amethystinus. Figures 34-35, 37, 40-42 stained with ink to visualize the mucilage. Bar $=10 \mu \mathrm{m}(34-38,40-45)$; $50 \mu \mathrm{m}(39)$. 
less regularly arranged within the colonial mucilage; mucilage colorless, firm, homogenous, diffluent; cells spherical or hemispherical after division, sometimes with individual envelope around cells, 2.4-3.0 $\mu \mathrm{m}$ diam.; cell contents blue-green, homogenous.

Material examined: BRAZIL. Rio GRANDE do SUL: Palmares do Sul, Spillway, 7-V-2003, LCTorgan s.n. (HAS104163); Tapes, Charutão lagoon, 2-XII-2003, SMAlves-da-Silva s.n. (HAS104416).

Comments: Reported for the first time in Rio Grande do Sul.
Chroococcus minutus (Kützing) Nägeli, Gatt. Einz. Algen. 46, 1849.

Figure 31

Colonies with few cells (2-4); cells solitary or microscopic, oval, elongated; mucilage colorless, firm, homogenous, sometimes lamellate, delimited; cells spherical or hemispherical after division, 5.0$7.5 \mu \mathrm{m}$ diam.; cell contents blue-green, homogenous.

Material examined: BRAZIL. Rio GRANDE DO Sul: Palmares do Sul, Casamento lagoon, 18-XI-2003,
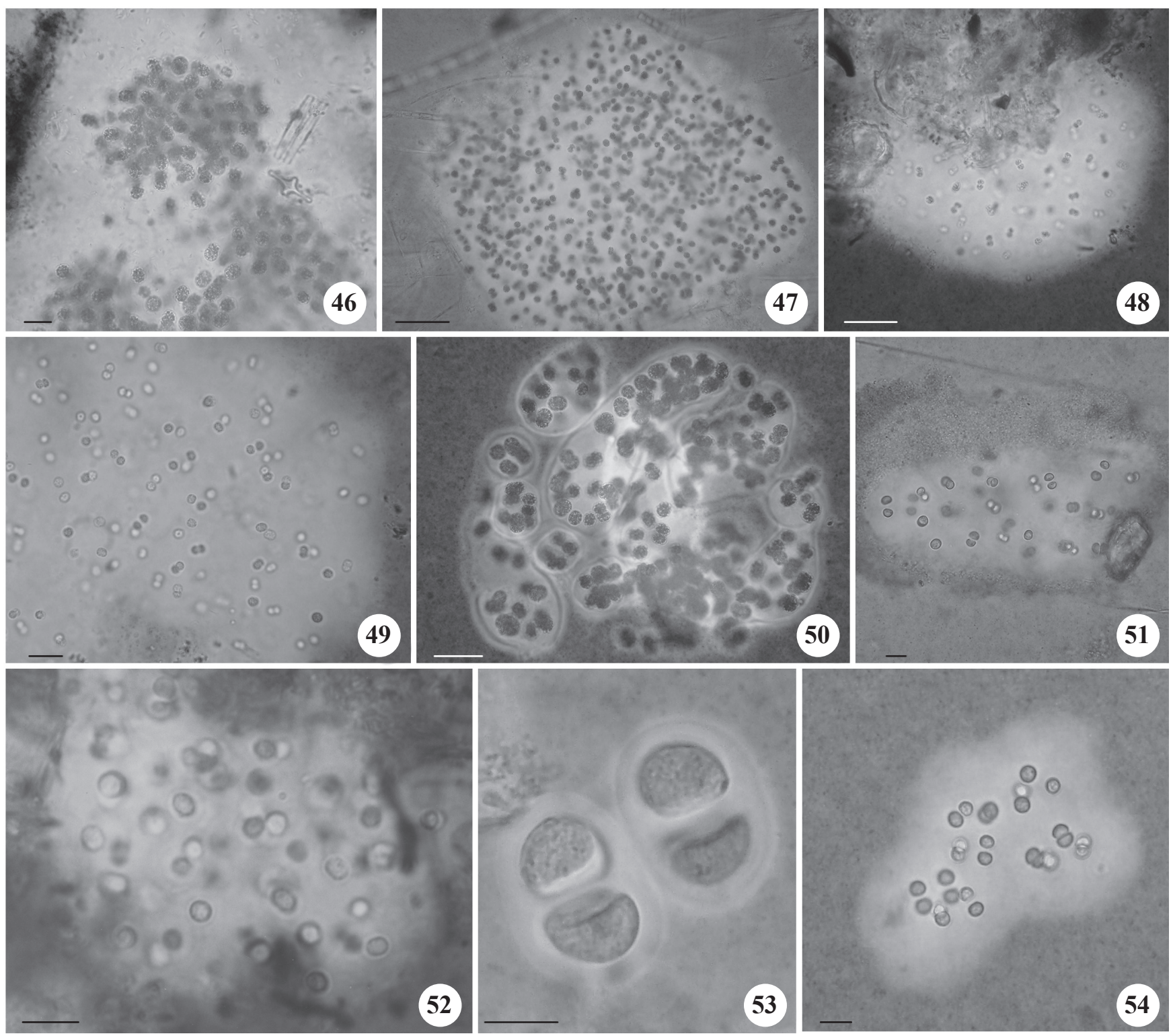

Figures 46-54. 46. Microcystis aeruginosa. 47. M. protocystis. 48. M. smithii (general appearance). 49. M. smithii (details of the cells and aerotopes). 50. M. wesenbergii. 51. Chroococcus distans. 52. C. minimus. 53. C. turgidus. 54. Limnococcus limneticus. Figures 46-54 stained with ink to visualize the mucilage. Bar $=10 \mu \mathrm{m}(46,49-54) ; 20 \mu \mathrm{m}(47-48)$. 
LSCardoso s.n. (HAS104352), 19-XI-2003, LSCardoso s.n. (HAS104356).

Comments: This species is widely reported from various biotopes throughout the world including mangrove swamps, aerophytic, and metaphytic habitats, thermal springs, and alkaline subtropical and tropical swamps, springs, creeks, and lakes. In this study it was observed in plankton.

Chroococcus turgidus (Kützing) Nägeli, Gatt. Einz. Algen. 46, 1849.

Figures 32, 53

Microscopic few-celled colonies (2-4 cells) that are oval, elliptic; mucilage colorless, firm, homogenous or lamellate, delimited; cells spherical or hemispherical after division, 8.0-12.5 $\mu \mathrm{m}$ diam.; cell contents bluegreen, homogenous or finely granular.

Material examined: BRAZIL. RIO GRANDE DO Sul: Tapes, Charutão lagoon, 3-VI-2003, VRWerner s.n. (HAS104202), 3-XII-2003, LSCardoso s.n. (HAS104451); Dunas wetland, 4/6/2003, VRWerner s.n. (HAS104234); Redonda lagoon, 4-VI-2003, VRWerner s.n. (HAS104235); Palmares do Sul, Capivari lagoon, 18-XI-2003, LSCardoso s.n. (HAS104343).

Comments: This species is widely distributed and has been reported from a great variety of habitats. Numerous taxonomic varieties have been described and probably represent a collective species.

Limnococcus limneticus (Lemmermann), Komárková et al., Hydrobiol., 639: 79, 2010.

Figures 33, 54

Colonies microscopic, oval, elongated or irregular, 40.0-60.0 $\mu \mathrm{m}$ diam., 60.3-85.5 $\mu \mathrm{m}$ long; cells irregularly arranged within the colonial mucilage, sometimes in indistinct groups (2-6 cells); mucilage colorless, firm, homogenous, diffluent; cells spherical or hemispherical after division, usually with individual envelope, 6.0$10.5 \mu \mathrm{m}$ diam.; cell contents blue-green, homogenous.

Material examined: BRAZIL. RIO GRANDE DO Sul: Capivari do Sul, Capivari lagoon, 5-V-2003, LCTorgan s.n. (HAS104098), 18-XI-2003, LSCardoso s.n. (HAS104343); Palmares do Sul, Casamento lagoon, 5-V-2003, VRWerner s.n. (HAS104103), 29-X-2003， SMAlves-da-Silva s.n. (HAS104396); Spillway, 7-V-2003, LCTorgan s.n. (HAS104167); Mostardas, Gateados laggon, 8-V-2003, LCTorgan s.n. (HAS104150, HAS104153), 19-XI-2003, LSCardoso s.n. (HAS104376).

\section{REFERENCES}

Bicca AB. 2007. A família Eunotiaceae Kützing (Eunotiales, Bacillariophyta) nas áreas da lagoa do Casamento dos Butiazias de Tapes, planície costeira do RS: taxonomia e distribuição. Dissertação de mestrado, Universidade Federal do Rio Grande do Sul, Porto Alegre.

Buell HF. 1938. The taxonomy of a community of bluegreen algae in a Minnesota pond. Bulletin of the Torrey Botanical Club 65:377-396.

Burger MI, Ramos RA. 2007. Áreas importantes para a conservação na planície costeira do Rio Grande do Sul. In Biodiversidade do Rio Grande do Sul: regiões da lagoa do Casamento e dos Butiazais de Tapes, planície costeira do Rio Grande do Sul (FG Becker, RA Ramos, LA Moura, eds.). Brasília, p.46-58.

Callegaro VLM, Rosa ZM, Werner VR. 1981. Comunidades fitoplanctônicas das lagoas Tramandaí e do Armazém, Tramandaí, Rio Grande do Sul, Brasil. Iheringia, Série Botânica 28:3-16.

Cardoso LS, Motta-Marques DML. 2003. Rate of change of the phytoplankton in Itapeva lake (North of Rio Grande do Sul, Brazil) based on the wind driven hydrodynamic regime. Hydrobiologia 497:1-12.

Cardoso LS, Motta-Marques DML. 2004. Structure of the phytoplankton community in Itapeva lake (North coast of Rio Grande do Sul, Brazil) and its relationship to hydrodynamic aspects: seasonal composition. Acta Limnologica Brasiliensia 16:401-416.

Franceschini IM. 1983. Levantamento das Nostocophyceae do rio Seco, Torres, Rio Grande do Sul, Brasil. Dissertação de mestrado, Universidade Federal do Rio Grande do Sul, Porto Alegre.

Franceschini IM. 1990. Flora de Cyanophyceae do Rio Seco, Torres, Rio Grande do Sul, Brasil. Napaea 7:1-39.

Franceschini IM. 1992. Algues d'eau douce de Porto Alegre, Brésil (les Diatomophycées exclues). Biblioteca Phycologica 92:1-82.

Garcia M, Vélez E. 1995. Algas planctônicas da lagoa Emboaba, planície costeira do Rio Grande do Sul: avaliação qualitativa. Boletim do Instituto de Biociências da Universidade Federal do Rio Grande do Sul 54:75-114.

Göneng IE, Wolflin JP. 2005. Coastal Lagoon: ecosystem processes and modeling for sustainable us and development. CRC Press, Boca Raton.

Hoffmann L, Komárek J, Kastovsky J. 2005. System of cyanoprokaryotes (cyanobacteria) - state in 2004. Algological Studies 117:95-115.

Joosten AMT. 2006. Flora of the blue-green algae of the Netherlands - I. the non-filamentous species of inland waters. KMNV Publishing, Utrecht.

Komárek J. 2006. Cyanobacterial taxonomy: current problems and prospects for the integration of traditional and molecular approaches. Algae 21:349-375. 
Komárek J, Anagnostidis K. 1998. Cyanoprokaryota 1. Teil: Chroococcales. In Süßwasserflora von Mitteleuropa 19/1 (H Ettl, G Gärtner, H Heynig, D Mollenhauer, eds.). Gustav Fischer, Jena-Sttutgart-Lübeck-Ulm, p.1-548.

Komárek J, Hindák F. 1988. Taxonomic review of natural populations of cyanophytes from the Gomphosphaeriacomplex. Archives of Hydrobiology/Supplement v.80, n.1-4, Algological Studies 50-53:203-225.

Komárek J, Kastovsky J. 2003. Coincidences of structural and molecular characters in evolutionary lines of cyanobacteria. Algological Studies 109:305-325.

Komárková-Legnerová J, Cronberg G. 1994. Planktic bluegreen algae from lakes in South Scania, Sweden. Part I. Chroococcales. Algological Studies 72:13-51.

Margalef R. 1969. Comunidades planctónicas en lagunas litorales. In Lagunas costeras, un simposio. Memorias del Simposio Internacional de Lagunas Costeras (A.A. Castanares, F.B. Phleger, eds.) UNAM-UNESCO, p.545-562.

Padisák J. 2003. Phytoplankton. In The Lakes Handbook. 1. Limnology and Limnetic Ecology (PE Sullivan, CS Reynolds, eds.). Blackwell Science, Oxford, p.251-308.

Sant'anna CL, Azevedo MTP. 2000. Contribution to the knowledge of potentially toxic cyanobacteria from Brazil. Nova Hedwigia 71:359-385.

Sant'anna CL, Azevedo MTP, Senna PAC, Komárek J, Komárková J. 2004. Planktic Cyanobacteria from São Paulo State, Brazil: Chroococcales. Revista Brasileira de Botânica 27:213-227.

Senna PAC, Peres AC, Komárek J. 1998. Coelomoron tropicalis, a new cyanoprokaryotic species from São Paulo State, Brazil. Nova Hedwigia 67:93-100.

Terwilliger K, Wolflin JP. 2005. Decision making for sustainable development coastal lagoons. In Ecosystem processes and modeling for sustainable land use and development (E Göneng, JP Wolflin, eds.) CRC Press, Boca Raton, p.331-370.

Torgan LC. 1997. Estrutura e dinâmica da comunidade fitoplanctônica na laguna dos Patos, Rio Grande do Sul, Brasil, em um ciclo anual. Tese de doutorado, Universidade Federal de São Carlos, São Carlos.

Torgan LC, Buselato TC, Ferraz GC. 1981. Floração de Aphanizomenon flos-aque (L.) Ralfs ex Born. et Flah. (Cyanophyceae) na represa de Itaúba, Rio Grande do Sul, Brasil. Iheringia, Série Botânica 26:45-64.
Torgan LC, Garcia M. 1989. Novas ocorrências (Cyanophyta e Chlorophyta) para a ficoflora planctônica no Rio Grande do Sul, Brasil. Hoehnea 16:57-64.

Torgan LC, Paula MCF de. 1994. Geitlerinema amphibium (Ag. ex Gom.) Anagn. (Cyanophyta-Pseudanabaenaceae) em um lago no sul do Brasil. Iheringia, Série Botânica 45:75-87.

Torgan LC, Garcia-Baptista M, Odebrecht C, Moller, OO. 1995. Distribuição vertical do fitoplâncton na laguna dos Patos, Rio Grande do Sul, Brasil (verão de 1986). Acta Limnológica Brasiliensia 7:67-77.

Werner VR. 1984. Cyanophyceae (=Nostocophyceae) planctônicas da Lagoa de Tramandaí e da Lagoa do Armazém, Rio Grande do Sul, Brasil: contribuição à taxonomia. Dissertação de mestrado, Universidade Federal do Rio Grande do Sul, Porto Alegre.

Werner VR. 1988. Cianofíceae planctônicas da Lagoa de Tramandaí e da Lagoa do Armazém, Rio Grande do Sul, Brasil. Iheringia, Série Botânica 37:33-70.

Werner VR. 2002. Cyanophyceae/Cyanobacteria no sistema de lagoas e lagunas da planície costeira do estado do Rio Grande do Sul, Brasil. Tese de doutorado, Universidade Estadual Paulista Júlio de Mesquita Filho, Rio Claro.

Werner VR, Rosa ZM. 1992. Cyanophyceae da Estação ecológica do Taim, Rio Grande do Sul, Brasil. Revista Brasileira de Biologia 52:481-502.

Werner VR, Sant'anna CL. 1998. Morphological variability in Gloeotrichia natans Rabenhorst ex Bornet et Flahault (Cyanophyceae, Nostocales) from southern Brazil. Revista Brasileira de Biologia 58:79-84.

Werner VR, Sant'anna CL. 2000. A new species of Aphanothece (Cyanophyceae, Chroococcales) from a shallow coastal lagoon, south Brazil. Nova Hedwigia 70:113-125.

Werner VR, Sant'anna CL. 2006. Occurrence of the rare genus Microcrocis P. Richter (Chroococcales, cyanobacteria) in a coastal lagoon from southern Brazil. Revista Brasileira de Botânica 29:183-186.

Werner VR, Sant'anna CL, Azevedo MTP. 2008. Cyanoggregatum brasiliense gen. et. sp. nov., a new chrococcal Cyanobacteria from southern Brazil. Revista Brasileira de Botânica 31:491-497.

Wetzel R. 1983. Limnology: lake and river ecosystems. 3 ed. Academic Press, New York. 